\title{
Undergraduates' Experience and Perceptions of Tourism and Hospitality Work Environments
}

\author{
Marija Rok \\ Faculty of Tourism Studies Turistica \\ University of Primorska \\ Obala 11a 6320 Portoroz, Slovenia \\ marija.rok@turistica.si
}

Doi:10.5901/ajis.2013.v2n2p61

\begin{abstract}
Intern experience can provide higher education institutions (HEI) valuable information on employers' relationships towards the younger workforce in the tourism and hospitality industry (THI). The main purpose of this article is to investigate how interns are treated during their placements. Are they considered to be the companies' future human capital, and thereby supported and stimulated to apply for jobs in the service industry that cannot prosper without devoted personnel? Novices and interns are always more vulnerable than more experienced personnel to the consequences of economic crisis and employer exploitation. Yet the tourism and hospitality industry constantly faces shortages of well-trained waiters, cooks, receptionists, animators, chambermaids, and other workers. A survey was carried out among interns that reveals reasons why some students during their study decide to leave the tourism and hospitality industry (or not enter it at all). We investigated their overall attitudes towards internships and their perceptions of conditions within the tourism and hospitality industry. The survey was conducted with a sample of students who completed placements in various tourism companies. A questionnaire seeking information on their satisfaction and circumstances of learning in the workplace was developed and distributed to them. The results of the content analysis provide useful information on employers' attitudes and the quality of working environments.
\end{abstract}

Keywords: tourism and hospitality industry; Slovenia; content analysis; internship; career.

\section{Introduction}

This paper reports the findings on the assessment of student experience and perception of work environments after their internships in the tourism and hospitality industry (THI).

As Dortch (2003) puts it, an internship is a structured learning experience in a work setting that provides a student the opportunity to learn about a career interest and gain valuable knowledge and experience in a particular field. The internship experience enables students to apply classroom theory to the actual world of work thus bridging the gap between theory and practice (Zopiatis, 2007). Hurst et al. (2012) emphasize that internships help students strengthen their marketable skills like communication, time-management, self-confidence, and self-motivation; all of them required by the industry. Through internships students gain direct access to job sources and lessen the reality shock when starting a transition from the university to the sphere of work. Students can thus integrate into the business environment and with experience gained they are far more employable and competitive on the labour market. Well performed internships often lead to a first job in the same company.

"The story of successful tourism enterprises is one that is largely about people - how they are recruited, how they are managed, how they are trained and educated, how they are valued and rewarded, and how they are supported through a process of continuous learning" (Failte Ireland, 2005, p.8). Yet, the tourism and hospitality industry worldwide faces the question as the means of attracting and retaining quality personnel. Therefore it would be expected that employers would provide considerable support and aid to interns while they became acquainted with the sector and the work processes and would strive for interns' respect and devotion.

This article provides some empirical evidence of the attitude of employers towards interns as well as towards other personnel from the viewpoint of undergraduates gaining work experience in the tourism and hospitality industry in Slovenia. 


\section{Theoretical background}

Across the OECD countries a pattern has emerged in which service jobs now provide between two thirds and three quarters of all jobs (SCER, 2004). As the tourism and hospitality services have become an indispensable part of the modern lifestyle, including human needs and values, the tourism and hospitality industry is rated as one of the fastest growing in the world. Accordingly, this industry needs qualified staff vital for the successful delivery of tourism services. Employers have realized that competitive advantages over competitors in the contemporary global economy can be achieved only by the quality of people they employ. High-quality services in the THI depend on the personnel's performance, behaviour and attitude. As Kapiki (2012) summarized this, appears that quality service is the basis for industry success.

In Slovenia all undergraduate professional programmes in the tourism and hospitality include compulsory professional training of students to complement the conventional classroom lectures. The forms of professional training are various, internships being the most important. They are also known as cooperative education, student work experience, placements (or sandwich placements), practicum or work-integration learning. Researchers and practitioners alike continue to endorse the value of internships and consider them a crucial component of higher education (Gault et al., 2010). In addition, Baum (2002) emphasized that traditional models of education and training for hospitality and tourism place considerable responsibility for skills development and the consolidation of learning on vocational work experience or internships.

Internships have been widely surveyed among authors (Hurst et al., 2012; Tse, 2010; Rok, 2010, Horng et al., 2009; Johnson \& Ridley, 2009; Richardson, 2009; Zopiatis, 2007; Van Emmerik, 2004; Scholz et al., 2003; Jowett \& Stead, 1994). Authors have explored internship experience from the students' perspective learning the alarming fact that based on the internship experience students too often do not want to stay in the same career area (Chen et al., 2011; Richardson, 2008; Feldman \& Weitz, 1990). Additionally, Airey and Tribe (2005) noted that there is surprisingly little research on how an internship enhances one's career and employment opportunities. Hence, Gault et al. (2010) focused on the effects of internships on the marketability of intern students from the perspective of employers and found that graduates with internship experience have significantly more full-time job opportunities than non-interns. When exploring the employers' perspective researchers agree that their perceptions differ significantly from those of the students (e.g., Beggs et al., 2008). Furthermore, Rok (2010) drew particular attention to the position and status of intern mentors within $\mathrm{THI}$ companies and revealed that most of these mentors accepted mentor tasks somewhat lackadaisically as mentorships were not recognized, valued, or awarded.

Yet, the potential benefits of internships are multiple for all stakeholders, students, employers and academia. It is vital to understand the needs of all stakeholders in the internship system because a lack of fit between their expectations, hopes and demands can result in frustration on all sides. In order to promote a win-win relationship and to make the system more effective, all interests have to be identified and satisfied.

\subsection{Benefits of internships for student interns}

Benefits received by interns are of primary importance in evaluating internship programmes. Johnson and Ridley (2009, p.86) indicate several positive outcomes for interns associated with mentoring: "Salient benefits include more rapid professional development, greater satisfaction with training and one's career, faster promotion rates, larger salaries and total compensation packages, accelerated career mobility, and a stronger sense of competence and confidence in one's job." In addition, Van Emmerik (2004) also emphasizes the importance of developmental networking relationships which is probably most beneficial for interns. According to Aggett and Busby (2011), placement experience is more "saleable" in the graduate job market than other types of work experience. Further, Harkison et al. (2011) calls it an opportunity to road-test theory, thereby creating the possibility for students to discover for themselves how the industry operates, and what skills they need to acquire or develop. Internships also clarify students' interests and future career plans.

Most graduates lack work experience and internships can provide some. Mulcahy (1999) describes this process as a vicious circle into a carrier opportunity: cannot get a job without experience, cannot get experience without a job. However, some authors (e.g., Richardson, 2009) point out that the greatest influence on career decisions of potential hospitality employees is work experience, either structured or unstructured. But one of the concerns relating to casual work or internships is that while this experience may be beneficial, it is not when students are be given menial, boring tasks instead of exciting and worthwhile projects. As Bould et al. (in Richardson, 2008) warned, the experience may 
actually lead to the students not pursuing a career in the industry at all. Hence, internships have to be carefully planned, organized, monitored and evaluated, students have to be trained in diverse departments and companies performing meaningful tasks.

\subsection{Benefits of internships for academia}

The advantages of internships for academia are connected mostly with the promotion of their study programmes and graduates, with possibilities to establish and maintain links with the industry and thus to enable and foster other ways of cooperation with them. Chen et al. (2011) also suggested that colleges may benefit by improving their overall academic performance through exposure to new technology and service concepts from industry.

\subsection{Benefits of internships for employers}

Among the benefits brought to employers, authors (Jowett \& Stead, 1994) report possibilities to solve staff shortages, select and recruit the best students, reduce the turnover of personnel, make use of fresh ideas and new approaches to existing problems and strengthen ties with academia. Interns are a future source of personnel with qualified experience. Hence, Hurst et al. (2012) consider interns a readily available, specifically trained workforce that has the potential to make an immediate impact on the host organization and can be a critical source of labour in today's recovering economy. In this regard, the authors stress that due to projected workforce exits of Baby Boomers, companies need to identify strategies for recruiting and retaining the best and brightest candidates.

\section{Research methodology}

A survey was conducted on a sample of interns who had just completed their internships within the tourism and hospitality organizations at the end of their fourth or fifth semester of study. This timing was determined assuming that students at this stage have acquired some of the prerequisite knowledge and skills to enter professional activities. As a part of their study programmes they are required to undertake a 2 to 4 month internship in the tourism and hospitality industry. Beforehand, students attend a short practicum at the faculty, a session preparing them to obtain the appropriate employer, assignments and performance. Students choose the area and organisation on their own, whilst the faculty also secures some possible placements and advertises them to students.

The internship is a part of the faculty curricula and is evaluated, graded (pass/fail) and credited after reviews by the faculty teacher in charge of practical training. Interns must present a written report and a certificate from the employer.

\subsection{Participants}

Our population consisted of a cohort of undergraduate students of professional study programmes for a 3-year bachelor's degree at the faculty of tourism studies who were due to carry out an internship in the previous academic year. A sample comprised all students (113) who successfully completed the internship programmes and earned credits. They were mostly (80\%) enrolled full-time, $76 \%$ were females. Internships were taken within the public (31\%), private (64\%) and voluntary (5\%) sectors. The duration of internships was between 240 in 420 hours, depending on the study programme.

Students were contacted in January 2013 via e-mail that comprised a link to the questionnaire and asked that they undertake the survey. Follow-up e-contacts were made in February 2013. 74 questionnaires were completed, 68 were useable, yielding a response rate of $60 \%$. With the data obtained we tried to find out whether our hypotheses could be rejected or accepted.

\subsection{Hypotheses}

In the present study, we express relationships between internships and their impacts on students development and career decisions through the following hypotheses:

- H1 Internships enable knowledge transfer and improvement of students' competences

- H2 Internships have a positive impact on the students' job performance 
- H3 Internship experience is positively associated with the students' decision regarding employment within the tourism and hospitality industry

- H4 Working time in TH has a negative impact on the students' satisfaction with internships

- H5 Students have negative perceptions of the tourism and hospitality organisations' culture

Objectives of this analysis derive from several perceived problems concerning students' complaints regarding practical training within the $\mathrm{THI}$, their unrealistic expectations and lack of adaptability to ever-changing work circumstances within the industry. The first problem has been frequently mentioned in evaluation analyses, students asserting that study programmes do not prepare them for practical experience and that they therefore have little chance to express their expertise. Secondly, when commencing placements without any previous experience they do not reckon with having to master basic operational work first. Only those who perform well will be entrusted with more demanding tasks. Operational tasks often include servicing guests who are not easily pleased or satisfied. It takes a lot of energy, nerve and patience to demonstrate service quality. Students are not prepared for trenuous work schedules, work under pressures and stress.

In Slovenia there is also a low valuation of manual occupations, which is deeply embedded in the culture. Svetlik (in Rok et al., 2011) claims that this has not changed in spite of the new technologies applied in several occupations which make work easier and more interesting. Interest on the part of domestic people in such occupations is lower and lower. As a consequence, jobs and occupations at the lower levels of the occupational scale are taken by immigrants and marginal groups; many occupations of this kind are in the hospitality industry. Similarly Baum (1996) speaks about nonattractive jobs in the industry and draws attention to substantial numbers of unskilled and semi-skilled workers in the THI. The author concludes that this might explain its reputation as an industry fraught with low paying jobs and poor working conditions. Baum challenged managers of tourism businesses to give those less exciting jobs the dignity and respect they deserve so that employees can be motivated to perform their tasks.

\subsection{Variables}

In evaluating interns' experience we examined three major sets of attitudinal variables: attitudes towards the internship, attitudes towards the tourism and hospitality working environments and attitudes towards employers in THI.

The questionnaire sought answers to seven key components of internship experience, comprising 56 statements on:

- Overall satisfaction with internships

- Attitude towards interns and opportunities for learning

- The quality of internships

- Working time

- Rewards

- Chances for employment

- Organisations' culture

In terms of overall satisfaction with internships we examined four attitudes: general impressions, cooperation with contact persons, usefulness of experience and quality of stimulation in the workplaces. Attitudes towards interns and opportunities for learning referred to the possibilities for the use of knowledge from classrooms, chances to practice foreign languages, opportunities for new skills and knowledge, endorsement of student's wishes and ambitions regarding departments and type of work, employers' work with interns, helpful mentors and equal treatment of interns with regard to others. The quality of internships is linked with the job design: the extent of requirements, skill diversity, degree of autonomy at work, use of interns for solving company skill shortages and for routine, boring or unrewarding tasks. In terms of the work time we included statements about the contentment with work schedules, week-end work or divided schedules as well as un-paid overtime work. Rewards included payment for internships, compensation for food and transport costs as well as other rewards. Chances for employment included engagements of students after internships, seasonal work, students' interest in the industry or decisions to leave it. In terms of organisational culture we examined the commitment of the staff, their collegiality, their professional attitude towards guests, the extent of stress among personnel, the management attitudes, promotion potential, praise, rewards, possibilities for harmonizing duties with family life, and possibilities for further education. At the end we asked students to list some good and bad sides of the completed internship.

The mean and standard deviations of 56 factors are shown in Tables 1-7. Measures were multiple-item five-point Likert scales, with responses ranging from 1 (I agree entirely) to 5 (I do not agree at all). Wherever possible, respondents 
were encouraged to give additional information and/or explanations.

The aim of the survey was to provide a comprehensive guide for employers and educators as to how young graduates judge the attractiveness of these service jobs, their weak points and to provide some avenues for improving their images. Students are good indicators of the hospitality and tourism industry work force opinion as they enter this industry observing it thoroughly while considering their first career path. Purposive sampling was chosen in order to obtain up-to-date impressions from those students who had recently accomplished this curricula obligation. However we have to point out that data obtained are of a subjective nature. These are the limitations of this research and due to a small sample, the findings of this analysis cannot be generalized beyond this study group.

\section{Research findings}

Findings reported in this section are:

\subsection{Overall satisfaction with internships}

Table 1. Students' overall satisfaction with internships

\begin{tabular}{|l|c|c|}
\hline & Mean & SD \\
\hline I was satisfied with the overall internship experience. & 1.9 & 1.1 \\
\hline Cooperation with contact persons in the company was good. & 1.9 & 1.0 \\
\hline I found the working environment in the company stimulating. & 2.3 & 1.1 \\
\hline The internship experience was beneficial for my further professional development. & 1.9 & 1.0 \\
\hline
\end{tabular}

$80 \%$ of students were satisfied or very satisfied with their internship and $82 \%$ believed that cooperation with contact persons was good. $67 \%$ of respondents appraised their working environments as stimulating. $73 \%$ of them believed that it would help them in their further professional career. These results do not match with findings of other research reported by Tse (2010) - namely there is a discrepancy between student perceptions of and satisfaction with internships.

But some interns did have a negative experience: "All I was assigned was administrative work, accounting and settling documents. It did not improve any of my competences. I was disappointed but was told that there was no one who would settle that."

\subsection{Attitude towards interns and opportunities for learning}

Table 2. Students' experience: relationships towards interns and knowledge transfer

\begin{tabular}{|l|c|c|}
\hline & Mean & SD \\
\hline The internship offered many opportunities to utilize learned theory and skills. & 3.0 & 1.1 \\
\hline The internship offered many opportunities to practice foreign languages. & 2.5 & 1.2 \\
\hline The internship offered many opportunities for new skills and knowledge. & 2.1 & 1.0 \\
\hline When making plans for my internship my ambitions and preferences were taken into account. & 2.5 & 1.3 \\
\hline The company was well-prepared for the reception and work with interns. & 2.2 & 1.1 \\
\hline My mentor in the company was very helpful. & 2.1 & 1.3 \\
\hline Co-workers helped me when getting acquainted with work tasks. & 1.6 & 0.7 \\
\hline The employer treated employees and interns equally. & 2.5 & 1.1 \\
\hline
\end{tabular}

Interns answered "neither agree nor disagree" to the statement that they could practice what they had learned in theory (rating 3), their remarks expressing disappointment on the work-ability gained at the faculty. They claimed that they could practice languages (2.5); they were especially satisfied with opportunities for new skills and knowledge (2.1). 61\% of respondents agreed that their ambitions and wishes were taken into consideration when making internship plans. $71 \%$ confirmed that their mentors were helpful, while $89 \%$ thought so of co-workers. When asked about the treatment of interns in comparison with other workers $54 \%$ found no difference and $31 \%$ could not agree nor disagree. Only a few had comments: 
"Everything was new to me and I did the same work as other students (employed part-time). We did the jobs of regularly employed staff who were on vacation. Unfortunately during this internship I found out that the faculty does not prepare students to be work-ready." Such statements confirm frequent industry remarks that education has to focus on developing essential work-ready skills while universities are more interested in development of intellectual capital. As Harkinson et al. (2011) noticed understanding the range and type of skills required by industry is important to both students and education providers. Outside-the-classroom learning improves mostly communication, interpersonal and intellectual skills.

\subsection{The quality of internships}

Table 3. Students' validation of the accomplished internship

\begin{tabular}{|l|c|c|}
\hline & Mean & SD \\
\hline After experiencing the internship I would recommend other students to engage in this company. & 2.3 & 1.2 \\
\hline The quality of internship depends a great deal on the initiative and motivation of the student. & 1.8 & 1.1 \\
\hline The degree of autonomy at work was accommodated to my competences. & 2.2 & 1.0 \\
\hline My work requirements followed well my competences gained at my level of study. & 2.7 & 1.2 \\
\hline The quantity of my workloads was appropriate. & 2.4 & 1.2 \\
\hline My work tasks were diverse. & 2.0 & 1.0 \\
\hline Interns perform only routine, boring and unpretentious tasks in this company. & 3.4 & 1.3 \\
\hline Interns' potentials are well-used in this company. & 3.2 & 1.3 \\
\hline Interns are used for solving skill shortages in this company. & 2.8 & 1.4 \\
\hline Students get a valuable insight into the company performance during internships. & 2.2 & 1.0 \\
\hline
\end{tabular}

The survey revealed that $22 \%$ of respondents complained that their work tasks were routine, boring or unrewarding. It seems that some employers do not take into consideration the fact that student interns need to recognize work tasks within the industry as diverse, dynamic and challenging. As one of the respondents commented:

"I was satisfied that workloads were demanding. The employer knew how to utilise intern potentials in the situation when they face staff shortages, which is good because interns will find out how the industry operates only when they are 'thrown into the water'. Thus you can make the best impression."

We found interesting the fact that $80 \%$ of the students agreed or strongly agreed that the quality of internship depends on them, $68 \%$ were satisfied with the amount of autonomy received as well as with the level of work requirements (58\%). $68 \%$ of them confirmed that they gained a good insight into the company performance.

\subsection{Working time in the tourism and hospitality industry}

Table 4. Students' perceptions of the working time characteristics

\begin{tabular}{|l|c|c|}
\hline & Mean & SD \\
\hline The working schedule was satisfactory. & 2.3 & 1.3 \\
\hline I do not mind working at weekends. & 2.0 & 1.1 \\
\hline I do not mind working on divided schedules. & 2.6 & 1.3 \\
\hline Overtime work in this company is often non-paid. & 3.2 & 1.3 \\
\hline
\end{tabular}

Surprisingly, most of the students did not complain about working schedules, week-end work or divided daily working hours nor about overtime work. But some employers abused the intern status; one intern stated:

"I do not mind working week-ends but I do mind working 10 days without a day off, and calls like: We need you in an hour! Come!" Such an attitude is far from desirable; to make these jobs attractive employers have to bear in mind Poon's words (cited in Baum, 2002, p. 348): "At every successful tourism establishment it is the employees that stand out... Technology cannot substitute for welcoming employees". Indeed, having skilled, enthusiastic and devoted 
personnel is vital for the prosperous THI. Therefore, the growth of the industry worldwide and employment shortfalls could be reduced by recruiting promising interns and graduates. Concurrently employers avoid the possibility of making a poor employment decision since they can observe the work of students throughout the internship period.

\subsection{Rewards in the tourism and hospitality industry}

Table 5. Students' experience about rewards

\begin{tabular}{|l|c|c|}
\hline & Mean & SD \\
\hline | received wages for the internship. & 2.9 & 1.6 \\
\hline I received only a minimum reward from the employer. & 3.3 & 1.5 \\
\hline The employer compensated transport costs to me. & 3.5 & 1.5 \\
\hline | received food. & 3.0 & 1.6 \\
\hline I received other compensations from the employer. & 4.2 & 1.2 \\
\hline | received no compensations for the internship. & 3.7 & 1.5 \\
\hline
\end{tabular}

$47 \%$ of interns received payment, but $72 \%$ confirmed that it was a minimum award, and only $29 \%$ received compensations for transport costs. $49 \%$ received meals. $14 \%$ received other forms of compensations (e.g., excursions). One of the respondents revealed an alarming attitude toward the young workforce:

"In this hotel interns do not receive meals. I was horrified by the fact that they would rather throw the food away than give meals to students. I felt sorry especially for young interns from the secondary school who worked really hard in the kitchen and were hungry. Who would not seek other career paths under such circumstances?"

Empirical data shows that wages in the industry are among the lowest in the national economy. Researchers (e.g., Lebe et al., 2009) agree that paying higher starting salaries is the most important step companies could take to attract more and better students to the tourism and hospitality profession. With low internship rewards (or none) it is hardly expected that graduates would be attracted to these occupations.

\subsection{Chances for employment}

Table 6: Students' experience of occupational circumstances

\begin{tabular}{|l|c|c|}
\hline & Mean & SD \\
\hline When I accomplished the internship I was offered a seasonal job in the company. & 3.0 & 1.6 \\
\hline After experiencing an internship I was offered employment in the company. & 4.3 & 1.1 \\
\hline $\begin{array}{l}\text { The internship experience strengthened my decision to obtain employment in the tourism and } \\
\text { hospitality industry. }\end{array}$ & 2.8 & 1.2 \\
\hline The internship experience made me reject career paths in the TH industry. & 3.9 & 0.9 \\
\hline I have never seriously considered working in the tourism and hospitality industry. & 4.6 & 0.6 \\
\hline
\end{tabular}

Only $6 \%$ of students were offered full-time employment at the end of the internship. We assume this low percentage is due to the on-going economic crisis, especially because $46 \%$ of interns prolonged their stay in the company for the high season. But some interns rejected it:

"The wages that they offered would hardly cover my transport costs. With such an attitude towards young workers I started to consider whether to stay in the sector. I lost motivation." Other researchers reported similar statements (e.g., Chen et al., 2011, p.72): "Some students felt that they had been treated as low-cost labourers in their internships."

When students were asked the likelihood that they would continue a career in the industry, $44 \%$ of the respondents agreed and $20 \%$ claimed that they would not pursue a career in the industry. Only $4 \%$ of respondents stated that the internship made them change their plans and leave the sector. None of them admitted that they never considered working in the industry. These findings indicate that students do enrol at the faculty with an aim to find positions in the 
tourism and hospitality industry, but one fifth of them change their mind during the study, only $4 \%$ due to negative experience from their internships.

\subsection{Tourism and hospitality organisational culture}

Table 7. Students' perception of the organisational culture

\begin{tabular}{|l|l|l|}
\hline & Mean & SD \\
\hline I noticed co-workers' devotion and their identification with the organisation's goals. & 2.4 & 1.1 \\
\hline Employees are exposed to a lot of stressors. & 2.6 & 1.4 \\
\hline The organisation of work was efficient in this company. & 2.3 & 1.0 \\
\hline Relationships among personnel were collegial. & 2.0 & 0.9 \\
\hline The employer had respectful attitude towards personnel. & 2.4 & 1.3 \\
\hline Employees were praised for well-done jobs. & 2.6 & 1.5 \\
\hline Promotion opportunities in this company were stimulating. & 3.4 & 1.5 \\
\hline Relationship towards guests was professional in this company. & 1.6 & 0.7 \\
\hline $\begin{array}{l}\text { The employer was helpful when employees' family and business obligations had to be } \\
\text { coordinated. }\end{array}$ & 2.9 & 1.7 \\
\hline The company enables further education and training to employees. & 2.4 & 1.4 \\
\hline
\end{tabular}

With these sets of statements we measured how interns perceived relationships within the company. $66 \%$ of respondents confirmed that industry personnel are devoted to their organisation and follow its goals. Concurrently, students noticed that chances for promotion were not stimulating (rating 3.4). 55\% of students noticed that the staff experience a lot of stress. Students graded the staff's relationship towards guests high (rating 1.6), as well as collegiality among personnel (2.0). Their general opinion towards the organisation of work was positive (2.3), the employers' attitude towards personnel was respectful (2.4) but ratings were less favourable regarding work adjustments to private life (2.9), awarding good performances (2.6), and enabling further education or trainings (2.4). We assume that such perceived circumstances do not deter students from seeking jobs in the industry. This does not correspond with findings of other authors (Chen et al., 2011) who revealed that students complained about having to perform menial tasks. Similarly, Waryszak (1999) posited that students got frustrated if internships were not fulfilling or aptly rewarded.

Our hypothesis that internships enable knowledge transfer and improvement of student's competences can be confirmed. The key characteristics of competencies is their efficient and creative utilisation in everyday life. Therefore, knowledge and skills are asserted only when through activities in certain environments are abilities valuated. Internships provide exposure to processes and problems which cannot be encountered in the classroom. Simultaneously, participation in internships prevents students from »reality-shock« that non-interns often face when they begin their first jobs.

The second hypothesis, that internships have a positive impact on the students' job performance, can be confirmed as well. Respondents expressed satisfaction with experience gained; their remarks prove that this affected positively their self-confidence and self-motivation. Before commencing internships students always have considerable expectations. Evaluative faculty research (Rok, 2010) indicated that they missed more practical training in the curriculum, especially outside-the-classroom forms; graduates expressed the same opinion. We assert that the faculty should take into consideration the power of alumni opinion to create suitable changes in study programmes.

The third hypothesis, that internship experience is positively associated with the student's decision regarding employment in the industry can neither be confirmed nor disproved. While $47 \%$ of respondents agreed to plan employment in the industry, other interns either did not agree or were indecisive (ratings 2.8). Fortunately, these findings do not tally with Jameson (in Chen et al., 2011) who claims that the more internship experience students get during college years, the less likely they are to want to work in that field on completion of their studies. Similarly, several authors (Richardson, 2009, Riley et al., 2002) report about graduates leaving this industry or even failing to enter it due to low job satisfaction, poor employment conditions and an absence of motivating factors resulting in high staff turnover and wastage of trained and experienced personnel. That is why it is advisable to spend a certain amount of time during the study practicing in the industry. 
We have failed to confirm the fourth hypothesis, that working time in TH has a negative impact on the students' satisfaction with internships. Students agreed or strongly agreed (73\%) that they were satisfied with work schedules, and did not mind working on week-ends (75\%) or having divided workdays (56\%).

Further, the fifth hypothesis, that students have negative perceptions of the tourism and hospitality organisations' culture can neither be confirmed nor disproved. Students expressed a realistic assessment of the situation in the THI; they were well aware of poor promotion chances, awards and other investments in human resources. At the same time they noticed diligence, devotion and collegiality among personnel. They were satisfied with the established relationships with co-workers, appreciated their help and support and noticed their professionalism towards guests in spite of all the burdens of the occupation including the employers' not being family-friendly. We posit that these factors had significant influence on their overall general satisfaction with internships.

\section{Discussion and conclusions}

This research was based on faculty intern students' experiences and was intended to provide valuable data for HEls and employers in the tourism and hospitality industry in Slovenia. The findings indicated that real-world experience was vital for the students' preparatory step into tourism and hospitality careers. The results verified that the hypotheses were supported when speaking about positive impacts of internships on students' competence development and job performance whereas the working time in $\mathrm{TH}$ has no influence on their career choice. Hypotheses regarding the students' negative perceptions of the THI organisations' culture could not be confirmed nor disproved. Intern experience did not make them change their job plans.

The aims of the survey were thus achieved. Based on these findings we can conclude that contrary to other research (Chen et al., 2011; Richardson, 2008; Kusluvan \& Kusluvan, 2000; Feldman \& Weitz, 1990) Slovene students do not contemplate careers outside THI. Considering the constant problem of attracting and retaining quality personnel in the industry these findings place considerable pressure on $\mathrm{HEI}$ and employers to collaborate more effectively to ensure that internship experiences are positive and valuable for students.

However there is room for improvements. We recommend that the faculty improves approaches to the application of theory to practice through internships and other forms of practical training, like shadowing professionals, project work, etc. The system of internship preparation and instructions has to be strengthened in order to provide better communication for student interns. Data showed that some students had unrealistic expectations about the tasks internships should provide. Some comments of respondents indicate that they could be better equipped to enter the realworld sectors, to integrate socially, to develop work values and to attain professional expertise. On the other hand the industry did not fully utilise the potential of interns. Employers have to create a positive internship experience if they want to recruit students upon their graduation. In order to attract better students, paying higher starting wages is the most important step companies could take, a process that could actually start by allotting fair awards for outstanding performances by interns. Working conditions in the industry are not favourable, but employers should endeavour to make the industry attractive for young people as well as to retain existing staff. According to interns' perceptions there are several opportunities in the field of HRM: e.g., stress management, the reward and compensation policy, lifelong learning, etc.

TH industry today offers a host of opportunities. The expanding economy has produced a larger number of new businesses. Potential students should be made aware of such information. Educators and practitioners must continue to reinforce the image of the profession. Perhaps, because of recent events, more students will select tourism and hospitality as a safe field of study offering vacancies.

This survey provides empirical evidence of the effects of internships in THI on students' standpoints and career decisions. We emphasize that the sample was taken from a single faculty of tourism and therefore may not be applied to all tourism and hospitality students in the country. Findings cannot be generalized due to the small sample size.

The results of this survey should be of interest to faculty teachers, employers, as well as students. Further research involving future interns is necessary including other educational institutions in $\mathrm{TH}$ in order to regularly check changes in relations and attitudes among stakeholders and to measure effects of new approaches to the preparation of students. Future research should also provide insight regarding the supervisors' perceptions of concluded internships in order to compare the standpoints of these two groups of stakeholders. 


\section{References}

Aggett, M. \& Busby, G. (2011). Opting out of internship: perceptions of hospitality, tourism and events management undergraduates at a British University. Journal of Hospitality, Leisure, Sport \& Tourism Education, 10(1), 106-113.

Airey, D. \& Tribe, J. (2005). An international handbook of tourism education. San Diego, CA: Elsevier, Inc.

Baum, T. (1996). Unskilled work and the hospitality industry: myth or reality? International Journal of Hospitality Management, 15(3), 207-209.

Baum, T. (2002). Skills and training for the hospitality sector: a review of issues. Journal of Vocational Education and Training, 54(3), 343-363.

Beggs, B., Ross, C.M., \& Goodwin, B. (2008). A comparison of student and practicioner perspectives of travel and tourism internship. Journal of Hospitality, Leisure, Sport \& Tourism Education, 7(1), 31-39.

Chen, C.T, Hu, J.L., Wang, C.C. \& Chen, C.F. (2011). A study of the effects of internship experiences on the behavioural intentions of college students majoring in leisure management in Taiwan. Journal of Hospitality, Leisure, Sport \& Tourism Education, 10 (2), 61-73.

Dortch, D. (2003). A complete guide to internships. Washington Post. Retrieved December 12, 2012, http://www.washingtonpost.com/wp-dyn/articles/A16305-2003Mar12. html.

Failte Ireland. (2005). A human resource development strategy for Irish Tourism. Competing through People, 2005-2012. Dublin: Failte Ireland.

Feldman, C.D. \& Weitz, B.A. (1990). Summer Interns: Factors Contributing to Positive Developmental Experiences. Journal of Vocational Behavior, 37, 267-284.

Gault, J., Leach, E., \& Duey, M. (2010). Effects of business internships on job marketability: the employer's perspective. Education+Training, 52(1), 76-88.

Harkison, T., Poulston, J. \& Kim, J-H.G. (2011). Hospitality graduates and managers: the big divide. International Journal of Contemporary Hospitality Management, 23(3) 377- 392.

Horng, J.-S., Teng C.-C. and Baum, T.G. (2009). Evaluating the quality of undergraduate hospitality, tourism and leisure programmes. Journal of Hospitality, Leisure, Sport and Tourism Education, 8(1), 37-54.

Hurst, J.L., Good, L.G. \& Gardner, P. (2012). Conversion intentions of interns: what are the motivating factors? Education+Training, 54(6), 504-522.

Johnson, B. W. \& Ridley, C.R. (2009). The elements of mentoring. Basingstoke: Palgrave Macmillan.

Jowett, V. \& Stead, R. (1994). Mentoring Students in Higher Education. Education + Training, 36 (5), 20-26.

Kapiki, S. (2012). Current and Future Trends in Tourism and Hospitality Industry, The Case of Greece. International Journal of Economic Practices and Theories, 2(1), 1-12.

Kusluvan, S. \& Kusluvan, Z. (2000). Perceptions and attitudes of undergraduate tourism students working in the tourism industry in Turkey. Tourism Management, 21, 251-269.

Lebe, S.S., Rok, M., Milfelner, B., Cvikl, H. et al. (2009). Establishing a contemporary model of human resource management for the tourism industry. Research project within the Target research programme "Competitiveness of Slovenia 2006 - 2013". Ljubljana: Ministry of Economy and ARRS.

Mulcahy, J.D. (1999). Vocational Work Experience in the Hospitality Industry : characteristics and strategies. Education and Training, $41(4), 164-174$.

Richardson, S. (2009). Undergraduates' perceptions of tourism and hospitality as a career choice. International Journal of Hospitality Management, 28, 382-388.

Riley, M., Ladkin A., \& Szivas, E. (2002). Tourism Employment. Analysis and Planning. Sidney: Channel View Publications.

Rok, M. (2010). Internmentoring in the tourism and hospitality industry. In Proceedings of the International Conference Tourism and quality of life. Portoroz: Turistica, Faculty of Tourism Studies, 2011, 386-400.

Scholz, R.W., Steiner, R., \& Hansmann, R. (2003). Role of internship in higher education in environmental sciences. Journal of Research in Science Teaching, 41(1), 24-46.

SCER (2004). What every employer wants: Skills, attitude and appearance in Glasgow service jobs. Scottish Centre for Employment Research, University of Strathclyde.

Tse T.S.M. (2010). What do hospitality students find important about internships? Journal of Teaching in Travel \& Tourism, 10, $251-264$.

Van Emmerik, H.I.J. (2004). The more you can get the better. Mentoring constellations and intrinsic career success. Career Development International, 9 (6), 578-594.

Waryszak, R.Z. (1997). Student perceptions of the cooperative education work environment in service industries. Progress in tourism and hospitality research, 3, 249-256.

Zopiatis, A. (2007). Hospitality internships in Cyprus: a genuine experience or a continuing frustration? International Journal of Contemporary Hospitality Management, 19(1), 65-77. 